Chapter 10

\title{
Laryngeal Manifestations of Rheumatoid Arthritis
}

\author{
Stevan Stojanović and Branislav Belić \\ Additional information is available at the end of the chapter \\ http://dx.doi.org/10.5772/51730
}

\section{Introduction}

Rheumatoid arthritis is the most common inflammatory disease of joints. It is described as symmetric, persistent and destructive polyarthritis which is often followed by positive rheumatoid factor and/or positive results on anticyclic citrulined peptide immunoglobulins. The larynx is rarely considered affected, and the patients come at terminal phase of rheumatoid arthritis when the changes are so progressive and irreversible and the treatment is very difficult. The larynx is a part of upper respiratory system and an aerodigestive crossroads and is, therefore, often affected by pathological changes specific for rheumatoid arthritis. Damage of its anatomical structures and physiological functions happens in the early phases of rheumatoid arthritis, as many authors have written about it (Hart, 1966), which is manifested by different pathoanatomical and pathophysiological changes. Sequence and intensity of the symptoms' appearance depend on the size, localization, spread and duration of pathological changes in rheumatoid arthritis. Clinical picture of laryngeal manifestations of rheumatoid arthritis is characterized by numerous and various symptoms.Because of the perplexity and length of the symptoms' manifestations of this disease on other localizations of a human body, it is rarely thought about the laryngeal symptoms and signs when they are in the initial phase and of weak intensity. Patients with progressive symptoms and signs of rheumatoid arthritis in the larynx do not get routine examination by otorhinolaryngologists, but this disease is usually diagnosed only when breathing and/or swallowing are very compromised.One patient with rheumatoid arthritis in its terminal phase was treated at the ORL Clinic of the Clinical Center in Kragujevac. The disease was diagnosed by techniques of indirect laryngoscopy, microlaryngoscopy with the use of laryngoscopic claws, computered endovideostroboscopy and multislice scanner larynx examination. Previously, the patient underwent surgical tracheotomy because of asphyxia and very reduced breathing space. Modern diagnostics recommended by other authors include electromyography of the larynx with the aim of differential diagnostics of cricoarytenoid joint immobility because of the pa- 
ralysis of nervus reccurens of other etiology.With the aim of timely diagnostics of pathological changes in the larynx in the patients with the rheumatoid arthritis, a routine indirect laryngoscopy is necessary to be carried out. When otorhinolaryngologists notice reduced mobility of one half of the larynx, laryngomicroscopy, electromyography of the larynx, multislice scanner neck examination are recommended in these patients. In diagnosed laryngeal changes, the therapy of intra-articular injection of corticosteroids in every affected cricoarytenoid joint should be considered as a possibility.

\section{Larynx and rheumatoid arthritis}

Rheumatoid arthritis is a generalized disease, but because of anatomical, physiological and pathoanatomial characteristics of the larynx, this disease has its manifestations in the larynx. Clinical picture, diagnostics and therapy of rheumatoid changes in the larynx have their characteristics to which every clinician must pay attention when treating clinical manifestations of this disease on other localizations and organs. In RA, the larynx is affected in $25 \%$ of the patients (Dockery, 1991). Symptoms and signs of rheumatoid arthritis in the larynx must be noticed and treated adequately in its earliest phase. This is necessary for preventing the progress of the disease and manifestation of the symptoms and signs that are life threatening, while the ultimate effect would be bringing back the quality of life to a satisfying level.

\subsection{Anatomy and embryology of the larynx}

The larynx or voice box is located in the median line of the anterior neck. It is placed at the aerodigestive crossroads and is the beginning of lower respiratory system. It is a fibroelastic tube between the hyoid bone and trachea, whose external layer is made of cartilage and muscles, and internal layer is mucous. The larynx is tied by ligaments and muscles to the hyoid bone and, therefore, it follows its movements. The larynx extends from the third to the fourth cervical vertebrae. From its aperture on the front wall of the inferior pharynx, the larynx comes down through the anterior neck and continues its way through the trachea. Upper larynx border is presented by a free edge of epiglottis and aryepiglottic plicae. Lower edge of the cricoid cartilage makes the lower larynx border, Figure 1.

Topographically, hypopharynx with very mobile musculature is between the larynx and vertebral column at the back, while at the front, there is a gland thyroid on both sides of the larynx. Its anterior is covered with thin infrahyoid muscles.Voice box is tied and strained to scull base and lower jaw indirectly over the hyoid bone, suprahyoid muscles and fibroelastic connections. It follows the head and neck movements and it rises and descends while swallowing. Its angular prominence on the anterior neck is known as Adam's apple in men, and is more prominent than in women. Structure of the larynx is such that firm part is made of cartilages connected mutually as well as with other organs by fibrillar connections-membranes and jointsligaments. Muscles move cartilages one to another. Submucous layer is made of fibroelastic membrane and the interior is encased by mucosa with blood vessels and nerves. Epiglottis bends backwards and closes the opening of the larynx while swallowing. Cavity of the larynx 
or cavum laryngis at its frontal section reminds of a sandglass or two vertical funnels connected with their narrow ends, Figure 2. Upper floor or vestibule of the larynx is vestibulum laryngis that extends from the larynx aperture to upper plicae, so called false vocal cords - plicae vestibulares s. plicae vocales spuriae. Inferior mucous plicae or true vocal cords or plicae s. chordae vocales close the vocal gap or rima glottidis and it presents the entrance into the lower, subglottic floor of the larynx called cavum infraglotticum. Vocal cord is in its anterior, longer part, membranous and that part is called pars intermembranacea s. ligamentum vocale and in its posterior, shorter part it is cartilagenous and that part is called pars intercartilaginea s. processus vocalis. Rima glottidis or just glottis consists of vocal cords and vocal extention of arytenoid cartilage. The median floor consists of a mucous recessus or invagination which arises between the true and false vocal cords and it is larynx ventricle or sinus s. ventriculus laryngis Morgagni. That recessus between the plicae ventricularis and vocal cords has a role of resonator and its length is approximately $20 \mathrm{~mm}$ in men and $15 \mathrm{~mm}$ in women. Mucosa of the larynx ventricle external wall is full of glands or glandulae laryngis.

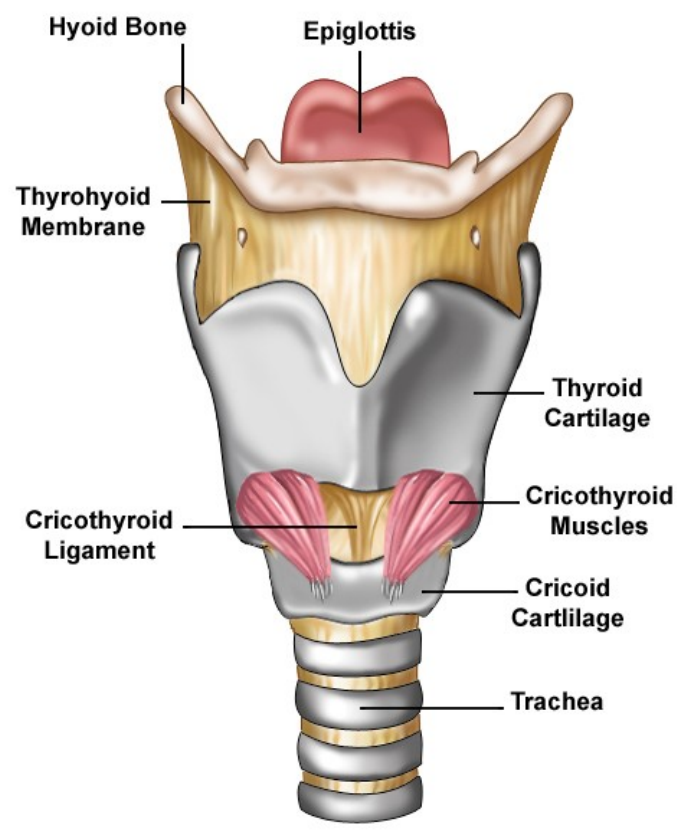

Figure 1. Anterior view of larynx. 


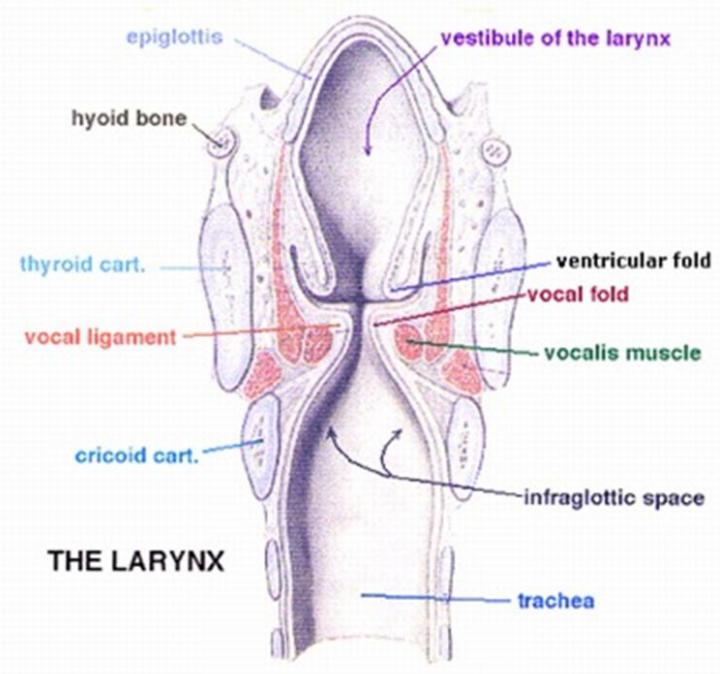

Figure 2. Coronal section of larynx.

\subsubsection{Epiglottis, plicae ventricularis and glottis}

The anterior side of epiglottis or pars lingulais is free and covered with weakly adhered mucosa, which allows easy stretchening around edema. Its posterior side called pars laryngis completely belongs to the larynx and is bent above the larynx aperture. Pedicle of epiglottis or petiolus is tied along the posterior side of the thyroid angle. Petiolus makes a bump on its mucosa, which covers the anterior commissure and, therefore, it can hardly be seen by indirect laryngoscopy. Mucosa of the epiglottic laryngeal side is tightly connected with its base. Vocal cords stretch from the back side of the thyroid angle and backwards to the vocal ending of the arytenoid cartilage, Figure 3.

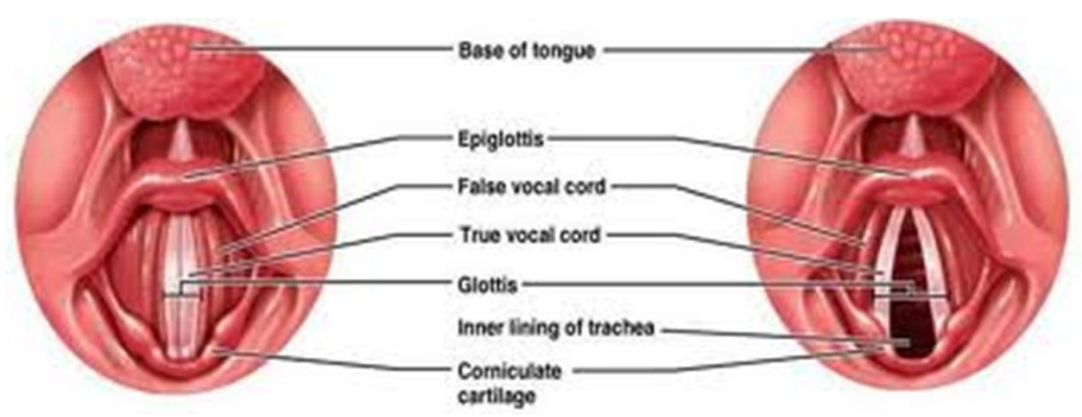

Figure 3. Internal view of larynx. 
They present triangular prismatic plicae. Their upper side is turned upwards and outside and continues its way laterally on the base of the ventriculus Morgagni, while their inferior side is turned downwards and inside and continues its way slopingly into the subglottic space. When seen microscopically, they are whitish with vertical capillaries. Vocal ligament makes elastic skeleton of the vocal cord. Length of the vocal cord is changeable and it depends on its position and tighteness. When calm, it is about $30 \mathrm{~mm}$ in men and $20 \mathrm{~mm}$ in women. Subglottic space extends from the vocal cords down to the inferior edge of the cricoid cartilage and it has a conical shape. Its mucosa is tightly connected to the cartilage and they are separated only by elastic membrane.

\subsubsection{Laryngeal cartilages}

Skeleton of the larynx consists of 16 cartilages: 6 paired and 4 unpaired. There are four large cartilages: thyroid or cartilago thyreoidea, cricoid or anular or cartilago cricoidea, paired arytenoid or cartilago arytenoidea and epiglottic or cartilago epiglottica. The first three are hyaline and the fourth one is fibrocartilagenous. The thyroid cartilage is the gratest cartilage of the larynx. It has a shape of a shield or a shape of a book opened backwards, Figure 4.

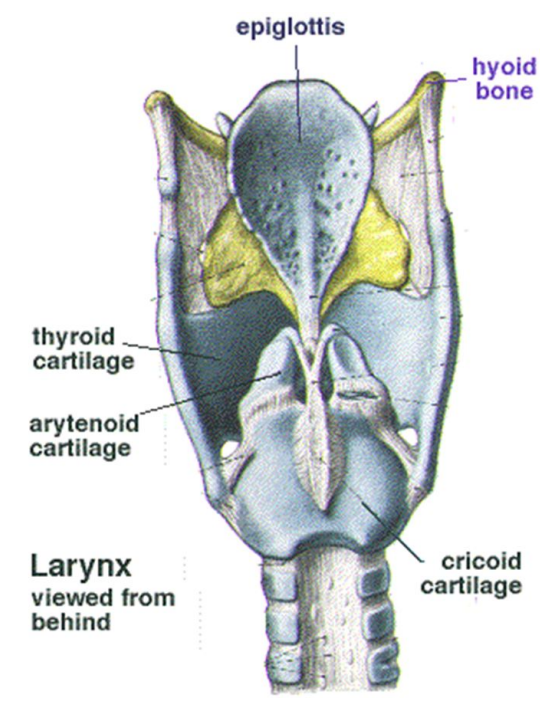

Figure 4. Lateral view of laryngeal cartilages.

Two thyroid quandrangle plates (lamine s. alae) are connected in their anterior middle part under the right angle in men and under 120 degrees in women. Plates become ossified around the age of 25 and the process ends around the age of 65. Its posterior edge extends upwards with the greater horn or cornu superior towards the hyoid bone and downwards with its interior side, little horn or cornu inferior is joined with the cricoid cartilage. The epiglottic cartilage is located in the anterior wall of the larynx and has a shape of a rose leaf. Its 
superior, wider part is the larynx lid, and lower narrower part is pedicle or petiolus. There are many concaves on the epiglottic cartilage that are filled with lymph tissue. The epiglottic cartilage is elastic and never ossifies in contrast to others that are hyaline and therefore start to ossify right after the puberty. Cricoid or anular cartilage is placed in the inferior part of the larynx. It has a shape of a ring which is narrow in front and wider in the back. Ossifying of this cartilage begins around the age of 65 . There are two small smooth surfaces for joining with arytenoid cartilages on both sides on the superior edges of cricoid lamina. The anterior cartilage is made of an arch or arcus. There are round surfaces for joining with inferior horns of the thyroid cartilage on the joining of the arch and lamina. Arytenoid cartilages are paired and they are placed in the posterior wall of the larynx. They have a shape of a triangular pyramid. The base of the pyramid is turned downwards and is located on the superior edge of the anular cartilage plate. On the inferior part, near the base of this cartilage, there are two extensions and one of them is turned medially or processus vocalis and the other one is turned laterally or processus muscularis. Musculus vocalis (m. thyroarytenoideus) attaches on vocal extension. Glottis adductors and abductors attach on the muscular extension. The main extension of the arytenoid cartilage extends with an elastic connection (ligamentum vocale) which extends forward and ends on the interior side of the thyroid cartilage under its superior incesure. Right above the anterior joint of this connection, another connection or ligamentum vestibulare begins, and it continues backwards and ends on the anterior edge of the arytenoid cartilage on one small protuberance or colliculus.

\subsubsection{Joints of the larynx}

There are two important joints on every side. They are synovial and enforced by a capsule. Articulatio cricothyreoidea is located between cornu inferior of the thyroid cartilage and cricoid cartilage on the joint of the arcus and lamina.

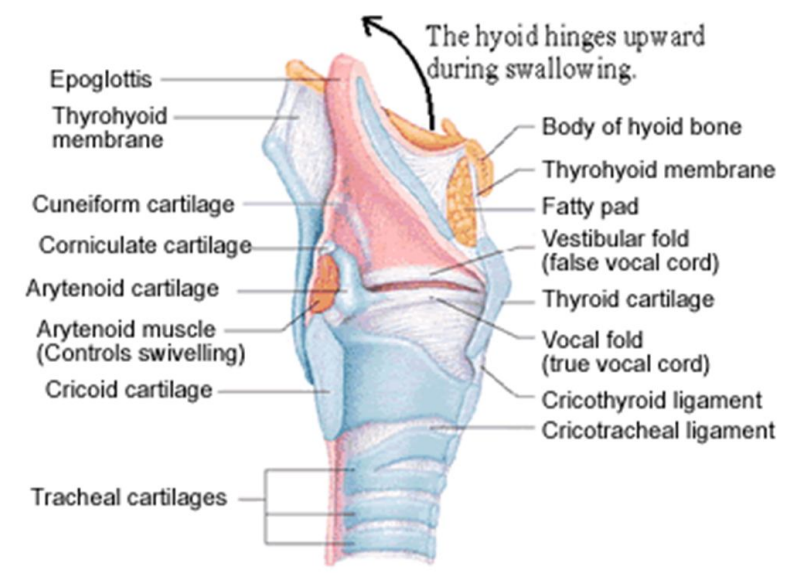

Figure 5. Joints of the larynx. 
Movements in this joint are rotation around the horizontal arytenoid axis and very restricted movements of sliding. Articulatio crycoarytenoidea is located between the arytenoid base and joint surfaces on superior edge of the cricoid cartilage. Movements in the joint are rotation around the vertical arytenoid axis and movements of sliding when arytenoids adduct or abduct, Figure 5.

\subsubsection{Fibrous links of the larynx - membranes and ligaments}

Membranes and ligaments of the larynx are divided into three groups. The first group consists of ligaments of joints' capsules, cricothyroid and cricoarytenoid. The second group consists of interior fibrous tissue made of memrane elastica laryngis. Superior membrane supports aryepiglottic and plicae ventricularis, while inferior membrane or conus elasticus goes between the superior edge of the cricoid and inferior edge of the thyroid cartilage up to behind the vocal extension. Ligamentum vocale presents superior, free edge of conus elasticus. The anterior part of the conus elasticus is tightly thickened in the middle and it makes ligamentum thyreoepiglotticum, which links epiglottis and thyroid cartilage. The third group consists of: membrane thyrohyoidea with the aperture for upper laryngeal artery and vein and internal branch of superior laryngeal nerve, cricotrachealis membrane lies between the inferior edge of the cricoid cartilage and the first tracheal ring and ligamentum hyoepiglotticum, which attaches epiglottis to hyoid bone, Figure 6.

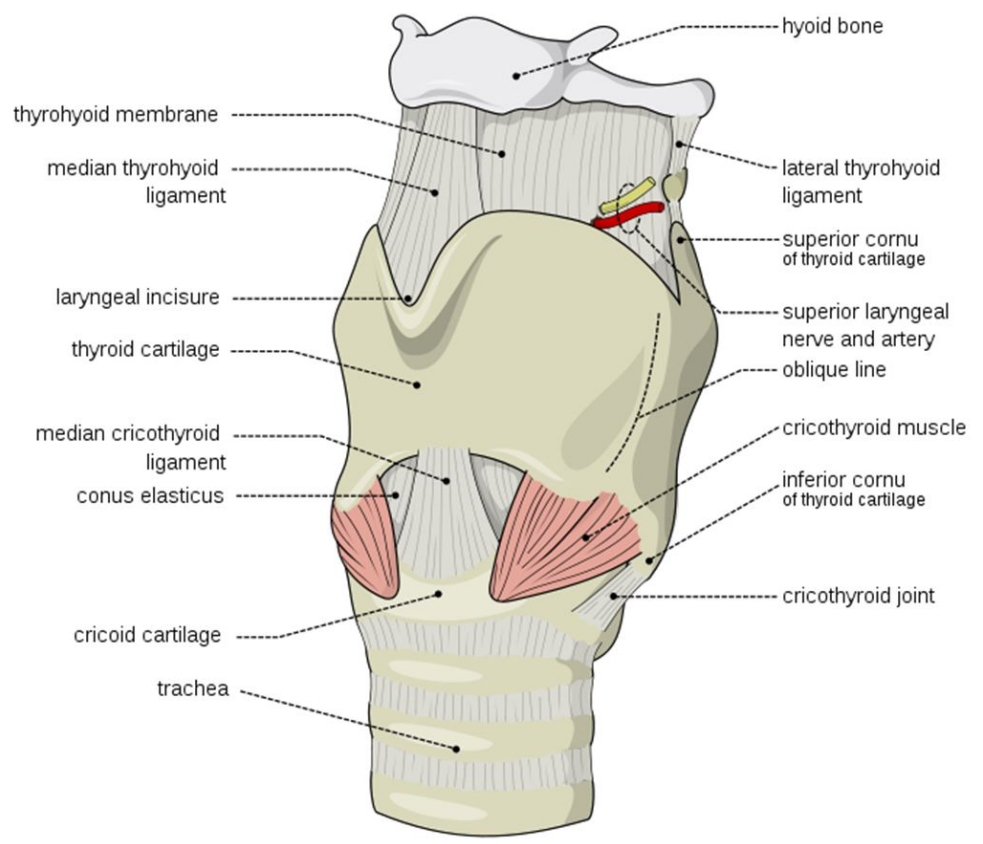

Figure 6. Membranes and ligaments of the larynx. 


\subsubsection{Muscles of the larynx}

Muscles of the larynx are divided into A. internal and B. external. A. Internal muscles (Figure 7) are placed between some of the cartilages and are divided into 1. abductors, 2. adductors, 3. tensors and 4. covers of the larynx lumen. 1. Laryngeal abductors are two muscles on each side of the larynx, m. cricoarytenoideus posterior s. posticus. Its function is to abduct vocal cords from the middle line and thus to open glottis. 2. Adductors adduct vocal cords to the middle line and close glottis. These are: a) m. cricoarytenoideus lateralis s. lateralis b) $\mathrm{m}$. interarytenoideus s. transversus c) $\mathrm{m}$. thyroarytenoideus or pars externa s. externus. 3 . Laryngeal tensors are: a) m. cricothyreoideus s. anterior is external laryngeal tensor. It adducts the thyroid cartilage to the cricoid cartilage from the anterior side, and thus tights the vocal cords intermediately. b) m. thyroarytenoideus or pars interna s. internus s. vocalis is known as internal larynx tensor and forms a vocal cord. 4) covers of the larynx lumen: a) m. interarytenoideus - pars obliqua has a role of glottic sphincter, b) m. aryepiglotticus represents an extension of pars transversa muscles interarytenoidus into aryepiglottic plicae and has a function of a supraglottic sphincter. B. External laryngeal muscles: a) m. sternothyroideus is pulling the larynx downwards, b) m. thyrohyoideus is raising the larynx if hyoid is fixed, in other words, lowering hyoid bone if the larynx is fixed.

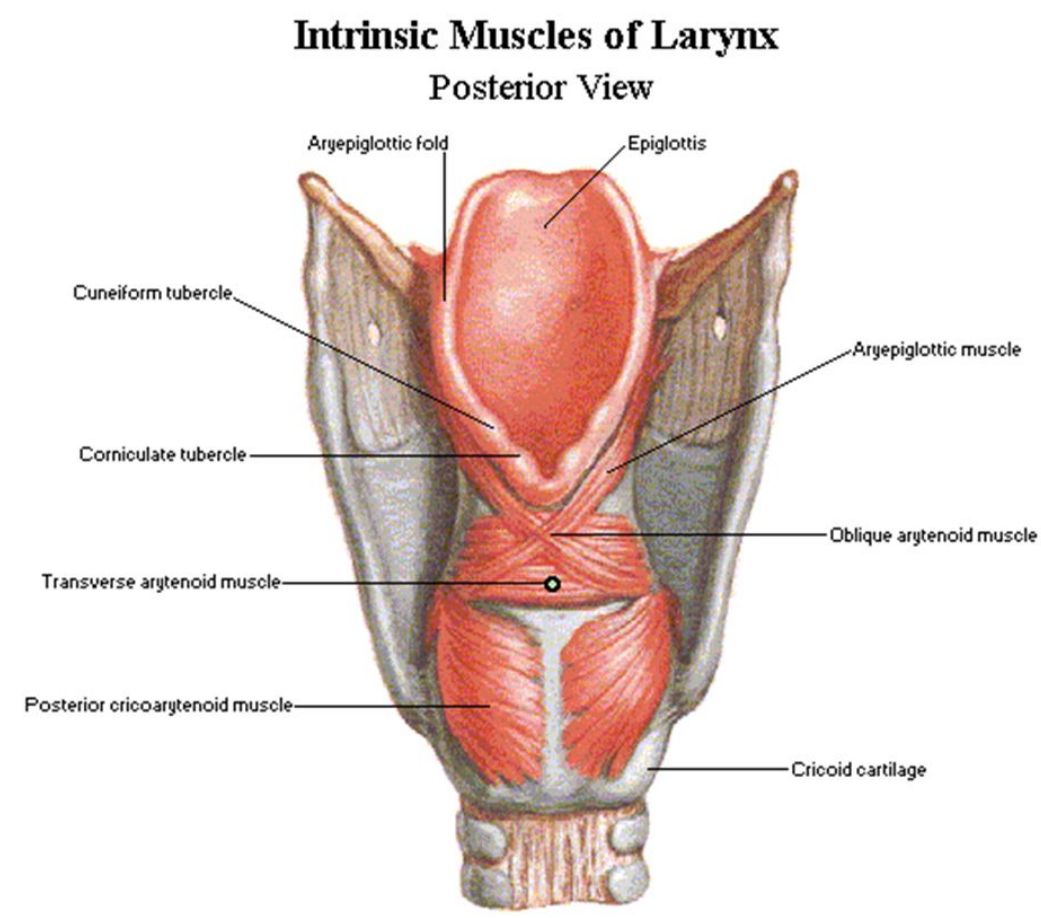

Figure 7. Internal laryngeal muscles. 


\subsubsection{Laryngeal mucosa}

Laryngeal mucosa encases the whole of its cavity. It is separated from cartilage and muscles by submucosa and elastic membrane. On the superior larynx aperture, mucosa continues its way forward across the superior edge and anterior side of epiglottis into the mucosa of the root of the tongue, laterally and backwards into the pharynx mucosa, then it encases the external surface of the anterior wall of the larynx and it continues downwards into the trachea. Laryngeal mucosa is tightened very loosely to submucosa and elastic aperture, except at the front on the epiglottic cartilage and at the back on Santorini cartilages and superior ends of the arytenoid cartilages. There are many tubuloalveolar glands of serous or seromucous nature. Apart from tiny glands that can be found almost everywhere in laryngeal mucosa, three main groups of glands are placed :a) on the top of laryngeal epiglottic side and in the root of the lingual side, b) in the wall of ventriculus Morgagni and c) in the plicae ventricularis. Otherwise, there aren't mucous glands on the free edges of the vocal cords. Larynx mucosa epithelium can be: 1) placoid-layered; 2) cylindrical-ciliary, respiratory type and 3) transitory pseudo-layered cylindrical epithelium (transitory type). Placoid-layered epithelium encases the vocal cords, superior larynx aperture and it goes downwards into the vestibulum, free epiglottic edge, epiglottic plicae, internal side of the arytenoid and interarytenoid space. This epithelium covers the whole glottis from the anterior commissure at the front and back to processus vocalis and interior side of arytenoid. It goes under the free edge of glottis and laterally towards the plicae ventricularis for 6 to $8 \mathrm{~mm}$. There are 20 to 30 rows of cells in that region. Under normal conditions, the isles of placoid epithelium can be found scattered in the zones of cylindrical-ciliary epithelium and in the larynx vestibulum. The passage between placoid-layered and ciliar epithelium in the level of the vocal cords and free edges of the larynx is manifested as transformation of superficial planocells into cylindrical cells. And opposite, in the level of placoid cells isle, these variations can continue one to another without the passage. The most important of all the layers is the superficial layer which is made of more planocells that desquamate but don't keratinize. Under the ifluence of toxins, chronic irritation and inflammation, this epithelium can show similar characteristics as horny layer and epithelium extensions go into the derm so that papillae become higher. Cylindrical-ciliary epithelium of respiratory type covers the remaining, largest part of the larynx surface.

In $20 \%$ of the cases, the anterior ends of the vocal cords are characterized by a narrow band of epithelium of transitory type. This epithelium is sometimes present in subglottis. Mucosa of the vocal cords has one macroscopic characteristic of a special importance like Reink spaces which goes along the whole length of the vocal cords between mucosa and vocal ligament. Macroscopically, there isn't a point of joining mucosa with a vocal ligament.

\subsubsection{Blood vessels, nerves and lymph vessels of the larynx}

Arterial vascularization of the larynx comes from: a) a. thyreoidea superior (branch a. carotis externa) via its branches aa. thyreoidea superior et media. These arteries go into the larynx on the posterior part of the thyrohyoid membrane, b) a. thyreoidea inferior (branch arteria subclavia) that follows n. recurrens on its way into the larynx. Veins of the larynx follow arteries of the same name. The larynx is innervated by the branch n. vagus: 1 ) n. laryngeus 
superior which has two laryngeal branches, internal and external (Figure 8). The internal branch is often sensitive and gives sensory innervation for the whole larynx lumen till the vocal cords height. It goes through the thyrohyoid membrane with superior laryngeal artery and vein. The external branch is motor and innervates the anterior cricothyroid muscle and goes along the inferior edge of superior pharynx constrictor; 2 ) n. laryngeus inferior s. recurrens which is on the left side much longer than on the right side. Left recurrens goes round the aortic arch and the right recurrens goes round the artery subclavia and then goes upwards in the gutter between the trachea and esophagus. It enters the larynx right behind the lower cricothyroid muscle and then divides into two branches: motor or anaetreolateral branch which innervates all internal muscles of the larynx, except the front cricothyroid muscle; and sensitive or postmedial branch for subglottic space. Nerve fibres n. recurrens that are on one side don't go on the opposite side. Lymph vessels of the larynx are divided into two parts, superior that are above the vocal cords or supraglottic and inferior, below the vocal cords or subglottic. Lymph vessels of the superior part flow into preepiglottic lymph nodes and superior deep neck lymph nodes. Lymph vessels of the inferior part flow into prelaryngeal lymph nodes and inferior deep neck lymph nodes. The vocal cords practically don't have their lymph vessels.

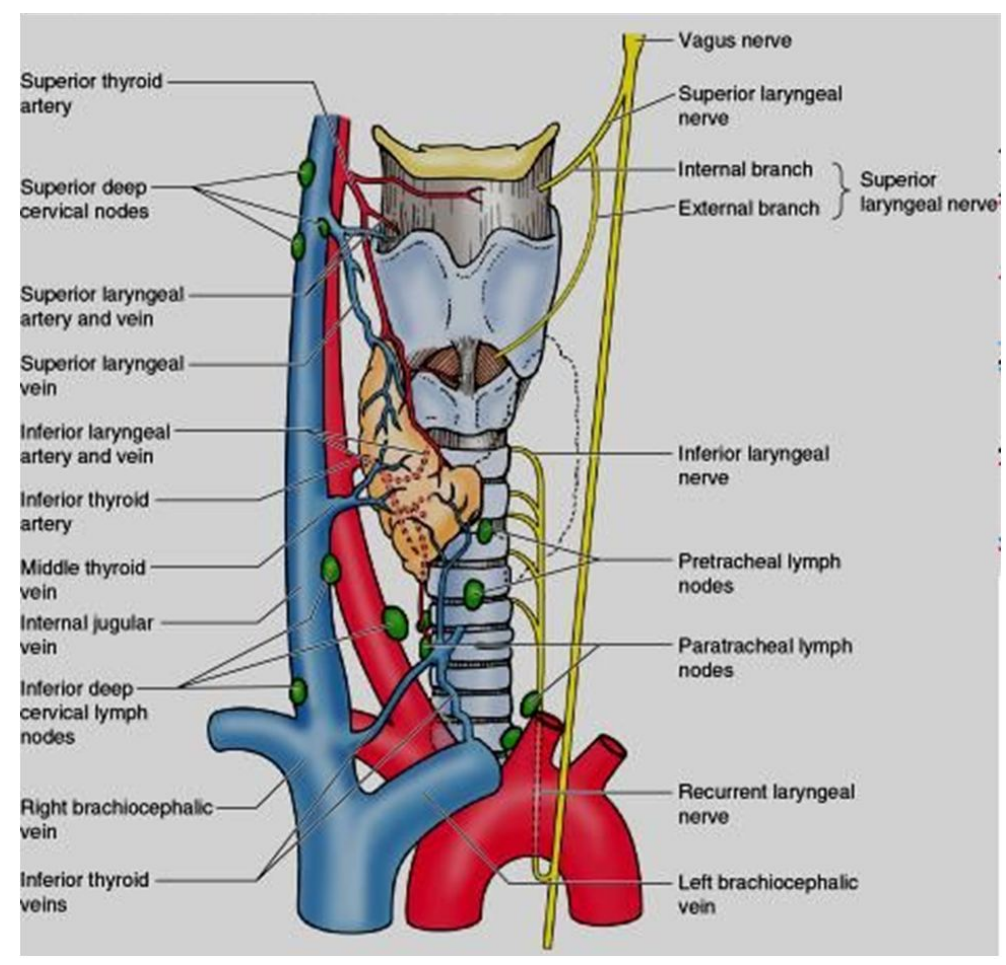

Figure 8. Blood vessels, nerves and lymph vessels of the larynx. 


\subsection{Physiology of the larynx}

Functions of the larynx can be primary and secondary. Primary functions are phylogenetically the oldest and they contain the following functions: respirations, protection of airways, swallowing, thorax fixation. Secondary functions are adapted to breathing and swallowing organs, ant the most important of them is phonation.

\subsubsection{Respiratory function of the larynx}

Glottis opens one second before the air comes into it by lowering diaphragm. This opening is a consequence of cricoarytenoid muscle contraction which is innervated by nerve recurrens and it begins right before the motor activity of $\mathrm{n}$. frenicus. It is led across the respiratory centre as the activity of $\mathrm{n}$. frenicus, it increases with hypercapnia and ventilatory obstruction, and it decreases with artery hyperoxygenation and hyperventilation. This activity is deleted by tracheotomy, as a result of lowered ventilation resistence. Hemoreceptor corpusculs are identified in supraglottic mucosa, so their stimulation during hypercapnia decreases laryngeal resistence during the inspiration and expiration. Inspiratory dilation of the larynx isn't distributed to glottis and it doesn't depend on muscle activity. With inspiratory lowering of the larynx from hyoid downwards, true and false vocal cords contract, arytenoid cartilages go laterally and glottis opens. Passive opening of the larynx is still intensified also by the inspiratory phase, in other words activity of external laryngeal muscles. The result of glottis opening size variation during respiration allows the larynx to contribute significantly to internal air resistance during the respiration time, so abduction of the vocal cords produces glottis dilatation and reduction of opening during the inspiration time, and adduction of the vocal cords with glottis constriction produces greater resistence to expiratory air, which influences the depth and level of respiration. These reflex changes are a consequence of reaction on presoreceptors in lungs and subglottic part of the trachea and can help in mixing the air in the lungs. After vagus deafferention, neither inflation nor deflation influence respiratory activity in posterior cricoarytenoid. Corrections of glottis opening compensate changes in total air resistance which increased in the nose and bronchi.

\subsubsection{Circulatory function of the larynx}

Normal respiration, in other words normal air circulation through the larynx, allows normal functioning of the circulatory system, heart and blood vessels. Arrhytmia, bradycardia and periodical cardiac arrest, can result in stimulation of the larynx. The mechanism is connected to the nerve fibres stimulation that comes from aortal baroreceptors and goes to the central nervous system across $\mathrm{n}$. laryngeus recurrens, ramus communicans and $\mathrm{n}$. laryngeus superior. These fibres go through the larynx into the deep tissue near thyroid plates and they are stimulated when the larynx is dilated.

\subsubsection{Protective function of the larynx}

Almost at the same time with respiration, mechanism of protection of the inferior airways developed, protecting them from entering foreign bodies, and this protection is guided by 
following mechanisms: 1 . Sphincter mechanism. There are three sphincters in the larynx and they are the vocal cords, ventriculous and aryepiglottic plicae so it comes to: adduction of the true vocal cords one to another, closing of the false vocal cords one to another and to the base of epiglottis, posterior commissure of the vocal cords is closed by rotation and adduction of the arytenoid cartilages, constriction of the false vocal cords by activity of internal laryngeal muscles, lifting and moving the larynx to the front, moving the base of epiglottis backwards and covering aditus, moving tyreoepiglottic ligamentum to the front. The previous movements, first of all the tongue base and aryepiglottic plicae, lead to direction of food bolus to peripheral sinus and thus allows the function of the larynx while swallowing; 2 . Reflex inhibition mechanism of respiration starts when food bolus touches the posterior wall of the pharynx and because of that, breathing stops immediately. Respiration ceases while swallowing. This is a reflex which results from stimuli coming from the pharynx when food enters, and they transfer via n. glossopharyngeus and n. vagus. Receptors are the richest in mucosa of the laryngeal side of epiglottis, aryepiglottic and plicae ventricularis and interarytenoid area; 3. Cough reflex is weak or it doesn't exist in newborn children. Reflex centre is in medulla oblongata, and n. vagus is both afferent and efferent part of the reflex arch. Closing of the false vocal cords is an important moment for this reflex, because adduction of the true vocal cords one to another can bring by itself to preventing the air to come out of the lungs. When high subglottic pressure is reached, sphincter mechanism suddenly relaxes and the air under the accumulated pressure comes out. In this way, matters that initiated this reflex also go out. 4. Phonatory function is secondary adapted to respiratory and swallowing organs. It developed later in phylogenetic development thanks to high differentiation of the central nervous system. For proper accomplishment of all the activities that the larynx carries out, there has to be full coordination of both synergistic and antagonistic groups of muscles. During phonation, the vocal cords are in adduction near medial line by the action of cricothyroid muscles that present the vocal cords tensors. More subtle changes are a consequence of thyroarytenoid muscles action. Medial movement of the vocal cords towards the false ones are caused by: a) tension in the vocal cords, b) lowering of subglottic air pressure with every vibrating aperture of glottis and c) aspirating the air that ran away which is known as Bernuli phenomenon. The result of such repeated cycles of glottis opening and closing is freeing of small clouds from subglottic air column which forms sound waves.

\subsubsection{Function of thorax fixation}

When the larynx is closed, thorax is fixed and serves as adminiculum when some activities connected to the effort are held out: climbing, lifting burden, defaecation, delivery.

\subsubsection{Function of emotions}

Different mental conditions are expressed over the voice or they cause disorder in it.

\subsubsection{Phonation function}

This function of the larynx is philogenetically the youngest function which was adapted to breathing and swallowing organs and it developed thanks to high diferentiation of the cen- 
tral nervous system. Production of voice is a very complex process and it depends on compliance in the body. It presents integral function in which peripheral and central phonatory organs take part in. Peripheral organs are: voice activator (lungs, diaphragm), voice generator (larynx) and resonator (pharynx, mouth, nose and paranasal cavities). Central organs for voice and speech are located in the central nervous system (cortex, lower centres, reticular substance, cerebellum and others). Voice and speech of the humans are under the influence of psyche, neurovegetative system and endocrine system. One of the most important preconditions for normal development of speech is preserved hearing. A system called "feed back" participates in forming and maintaining voice and speech. Besides hearing, its main elements are eyesight and sensibility, and main activities in the sense of creating voice and speech happen in the central nervous system. Three-dimensional analysis of movements in cricoarytenoid joint shows that vocal ligaments, cricothyroid ligament and conus elasticus are the most important in the control of abduction, while posterior cricoarytenoid muscle and conus elasticus take part in restriction of adduction. Vocal ligament makes moving of the vocal arytenoid cartilage extension backwards impossible, while cricoarytenoid and posterior capsular ligament restrict movement of vocal extension forward. Anterior capsular ligament restricts slanting of the arytenoid cartilage posteriorly and moving of the arytenoid cartilage laterally across joint surface of the cricoid cartilage (Wang, 1998).

\subsection{Etiology of rheumatoid arthritis and laryngeal rheumatoid arthritis}

Rheumatoid arthritis (RA) is an inflammatory chronic systemic disease of unknown cause that affects peripheral joints symmetrically and permanently and is often connected to positive rheumatoid factor and/or positive results on anticyclic citrulined peptide immunoglobulins.. Annual incidence of RA in the world is 3 patients out of 1000 people, and the prevalence is from $0,5-5 \%$. The disease is mainly present in some groups of population like North American natives, while it is less present in some other groups like black people in Carribean region. When gender is taken into consideration, the disease is three times more frequent in women than men. It can start at any age but its greatest frequency is in the fourth and fifth decade and it grows in the old age so it is the highest in people at the age of 25 to 50 . Arthritis rate is from 5-6\% in the Americans from Asian/Pacific islands, to 12\% in Afro-Americans to $16 \%$ in white people. Etiology of rheumatoid arthritis includes more assumed theories. One of them says that obesity, weakness and morning rigidity are important in appearing of this disease. Apart from joints, RA can also have extra-articular localizations such as skin, heart, lungs and eyes. Another etiological theory implies presence of infectious cause of rheumatoid arthritis (Mycoplasma, Epstein-Bar virus, parvovirus, rubella) but none of the mentioned micro-organisms has been proved. Some of the medications from the group of medications that modify the disease also have antimicrobical activity and they are gold salts, antimalarial medications and minocyclin. In the joints of rheumatoid arthritis patients, bacterial DNA is found, which is also an indirect proof of the bacterial etiology. Autoimmune processes, as one more theory out of the assumed etiological theories, are tightly connected to RA but it isn't known if they appear as a primary or secondary process. In the RA patients, autoantibodies aren't directed towards one immunoglobulin $G$ but also towards other different antigens, such as nuclear antigens (RA 33, EBNA), citrulined proteins (anti-CCP antibodies), collagen and glucose-6-isomarase phosphate. RA 
has an important genetic predisposition and that is one more theory about RA. About $60 \%$ of patients in the USA has a common epitope HLA-DR4 claster which consists of peptide connected place of the adequate HLA-DR molecule and it is joined with RA. As women suffer from RA about three times more often than men, sexual hormones explain one more etiological theory of RA. Complaints almost completely disappear during pregnancy, but in the postmenopause period, recurrences of the disease appear. RA rarely appears in women who use oral contraceptives. It is also described that hyperprolactinemia can be a risk factor for RA. Hyperplasia of synovial cells and activation of endothelial cells are early occurences in the pathological process that lead to uncontrolable inflammatory process and consequent cartilage and bone damage. Pathological production and regulation of both pro-inflammatory and anti-inflammatory cytokines are found in RA. In tissue immunity, the most important are Th1 CD4 cells, mononuclear phagocytes, fibroblasts, osteoclasts and neutrophils. B lymphocytes can serve as an antigen of the presenting cell and they create autoantibodies (for example rheumatoid factor $-\mathrm{RF}$ ). One of the therapeutic possibilities is, therefore, the elimination of B lymphocytes population by mononuclear antibodies (for example rituximab ${ }^{\mathrm{R}}$ which is often used in combination with methrotrexate). In RA patients, many other changed cells are found, such as numerous cytokines, hemokines. Other mediators of inflammation are also described: tumor necrosis factor-alpha, interleucins 1 and 6, transforming growth factor - beta, interleucin 8, fibroblast growth factor, growth factor received from thrombocytes. Finally, inflammation and uncontrolable synovial proliferation lead to damage of certain tissues, mostly cartilages, bones, strings, ligaments and blood vessels. Other predisposing factors are psychological stress and smoking. The so far known risk factors in RA are: female gender, positive family history, older age, exposure to silicates and smoking (Kuder, 2002). Drinking more than two cups of coffee a day, high intake of vitamin $\mathrm{D}$, consuming of tea and oral contraceptives reduce risk for RA (Mikuls, 2002; Merlino, 2004).

\subsection{Pathoanatomy of rheumatoid arthritis and laryngeal rheumatoid arthritis}

Damage of joints in RA is caused by proliferation of synovial macrophages and fibroblasts, probably as a response to possible autoimmune and infectious triggers. Therefore, it comes to lymphocyte proliferation of perivascular region and proliferation of endothelial cells which cause new blood vessels to multiply and ingrow. In damaged joints, blood vessels become clogged by small clots or inflammatory cells. Furthermore, the progress of process leads to irregular growth (Firestein, 2005; Goldring, 2000). RA in the larynx can manifest in the following forms: 1) Arthritis of cricothyroid and/or cricoarytenoid joint (Ferdynus-Chromy, 1977; Gotze, 1973; Kubiak-Socha, 1973; Woldorf, 1971; De Gandt, 1969; Copeman, 1968), 2) Rheumatoid nodules (Bridger, 1980; Bonner, 1977; Abadir, 1974), 3) Laryngeal myositis, 4) Neuropathy of laryngeal nervus recurrens and 5) Postcricoid granulomas (Bienenstock H, 1963). Histological examinations of cricoarytenoid joints in RA have shown synovitis as the earliest change that leads to synovial proliferation, fibrinous deposit, forming of pannus on joint surfaces, erosion of the joint cartilage and finally obliteration and ankylosis of joints. Cricoid necrosis as the last phase of pathological changes on the cricoid cartilage can cause serious pathophysiological disturbances (Gatland, 1988). Neural atrophy of laryngeal muscles and degenerative changes in laryngeal nerves caused by vasculitis, can follow the degree of affection of cricoarytenoid 
joint (Voulgari PV, 2005; Lofgren RH, 1962). Rheumatoid nodules of different size in the larynx are mainly found with seropositive RA. Methotrexate can raise the development of nodules (Kerstens, 1992). Microtrauma, especially a repeated one, can create predisposition for RA. In the largest number of cases, nodules are found subcutaneously. A few small nodules can be noticed microscopically in submucous layer, and each of them consists of fibrinous necrosis focus surrounded by histiocytes arranged like palisades. There is a progressive proliferation of endothelial cells and fibroblasts as well as the infiltration of plasma cells and lymphocytes in fibrous supporting tissue that surrounds nodules (Webb J, 1972).

\subsection{Pathophysiology of rheumathoid arthritis and laryngeal rheumatoid arthritis}

Factors joined with RA include the possibility of infectious trigger, genetic predispositions and autoimmune response. $\mathrm{CD} 4^{+} \mathrm{T}$ cells lead to immunological cascade reaction which causes secretion of cytokines such as tumor necrosis alpha and interleucin 1. Increased formation and expression of TNF-alpha cause inflammation of synovial membranes and joint destruction. Inflammation, proliferation and degeneration are typical for affected synovial membranes. Joint deformations and working inability happen because of erosion and destroying of synovial membranes and joint surfaces. Acute obstruction of the superior airways leads to inspiratory stridor, the use of subsidiary respiratory musculature which is manifested by entrainment in jugulum, intercostal spaces, supraclavicular pits and in epigastrium, respiratory weaknesses, peripheral cyanosis, state of shock and coma (Lehmann, 1997). Chronic obstruction of the superior airways can lead to hypoxia, hypercapnia and respiratory acidosis which cause pulmonary hypertension and cor pulmonale (McGeehan, 1989).

\subsection{Clinical picture of rheumatoid arthritis and laryngeal rheumatoid arthritis}

Clinical picture of RA can be divided into several groups of clinical manifestations of the disease, depending on the affected organs/systems: 1) Pulmonary, 2) Cardiovascular, 3) Constitutional, 4) Manifestations from rheumatoid nodules, 5) Eye manifestations, 6) Neurological, 7) Cutaneous, 8) Hematological, 9) Renal and 10) Hepatic manifestations. 1) Pulmonary manifestations of RA are pleuritic effusion, pulmonary nodules, interstitial fibrosis, pneumonitis and arteritis. 2) Cardiovascular manifestations are coronary disease, inflammatory pericarditis and pericarditis with effusion, myocarditis, mitral valves disease, disorder in conducting. 3) Constitutional manifestations of RA can be high body temperature, asthenia, weight loss, exhaustion and loss of appetite. 4) Rheumatoid nodules can manifest subcutaneously or in pulmonary parenchyma. 5) Eye manifestations are kretoconjuctivitis, episcleritis, scleritis and conjuctivitis. 6) Neurological manifestations of RA can be neuropathies such as carpal tunnel syndrome, multiple mononeuritis, cervical myelopathy, central nervous system diseases (stroke, hemorrhage, encephalopathy, meningitis). 7) Cutaneous manifestations in RA can appear as ulcus cruris, palmar erythema and skin vasculitis. 8) Hematological manifestations of RA appear as anemia, thrombocytosis, granulocytopenia, eosinophilia, cryglobunemia and hypertreaclines. 9) Renal manifestations can appear as glomerulonephritis, vasculitis and secondary amyloidosis. 10) Hepatic manifestations of RA are characterized by high level of liver enzymes. American association of rheumatologists has 
set up the following criteria for RA clasification: 1 . Rigidity in and around joints that lasts at least one hour before maximum improvement in the morning hours. 2. Arthritis of three or more joint regions. At least three joint regions have soft tissue swellings or liquid which was diagnosed by a clinician. Fourteen possible regions include left and right superior interphalangeal (GIF) joint, metacarpophalangeal (MCF) joint, wrist joint, elbow joint, knee joint, ankle and metatarsophalangeal (MTF) joints; 3. Arthritis of wrist joints; at least one region of carpus, GIF and MCF are swollen; 4 . Symmetric arthritis, in other words simultaneous affection of the same joint region on both sides of the body. Mutual affection of GIF, MCF and MTF without absolute proportion is also accepted; 5 . Rheumatoid nodules are subcutaneous nodules that are present above the osseus bumps or extensory surfaces or surfaces around the regions that are close to joints; 6. Serum RF; 7. Radiographic changes typical for RA on postero-anterior radiographies of hand and carpus, that have to enclose erosions or disproportional decalcification of bones localized in or on the rims of the most common affected joints. Independent osteoarthritic changes are not a criterion for RA. Presence of four out of seven criteria are enough for diagnosis. Criteria from 1 to 4 have to be present at least 6 weeks, and the physician has to establish criteria from 2 to 5. RA is often manifested with constitutional symptoms such as myelalgia, weight loss, high body temperature, weight loss and exhaustion. Patients can have difficulties with every day activities (dressing up, getting up, walking, personal hygiene, the use of arms). In most of the patients, RA has a perfidious start. It can start with systemic manifestations such as high body temperature, exhaustion, arthralgia and weakness before the appearance of swelling joints and inflammation. In the lower percentage, the patients have abrupt start with acute development of synovitis and extra-articular manifestations. Laryngeal manifestations of rheumatoid arthritis were described for the first time in 1880. by Mackenzie M. and later, 1894. Mackenzie GH. (Mackenzie, 1880; Mackenzie, 1894). Cricoarytenoid arthritis can be divided into two phases, acute and chronic, and it appears in $27-78 \%$ of RA patients (Tarnowska, 2004), and according to some authors in $17-70 \%$ when the research is done laryngoscopically, by computered larynx tomography and histopathological cadaveric examinations (Voulgari, 2005). In 55\% of patients, cricoarytenoid arthritis is asymptomatic (Jurik, 1984). At the beginning of the disease, symptoms are mild but usually subclinical. Acute cricoarytenoid arthritis is manifested by feeling of a foreign body in the throat or a feeling of tension in neck or even feeling of burning, hoarseness, odynophonia, voice weakness, changes in voice tone, odynophagia or dysphagia, pain or the feeling of hardness that becomes worse while speaking, spreading of pain to ear, feeling of suffocating, coughing, dyspnea or the feeling of rigidity. In the chronic phase of cricoarytenoid arthritis, patients often complain of hoarse speech, stridor that appears while making an effort, dyspnea, pain while speaking, neck swelling, hoarseness and these symptoms appear during an infection or during a dream (Braverman, 2007). Laryngeal symptoms during RA vary in their manifestations from $31-75 \%$, while histopathological changes in the larynx are presented postmortem in $90 \%$ (Pearson, 1957; Copeman, 1957). According to some authors, stridor appears during exercising in $75 \%$ of the cases (Charlin, 1985) and can be the result of inflammation and swelling of arytenoid and posterior commissure during an acute affection of joint or because of joint ankylosis in the chronic RA phase. The most frequent symptoms are the feeling of a foreign body in the throat $(51 \%)$, 
hoarseness (47\%) and voice weakness (29\%) (Amernik, 2007). Hoarseness appears only in $5 \%$ of RA patients (Fisher, 2008), while some other researches have shown that it appears in $30 \%$ of RA patients (Segebarth, 2007). Hard RA can be manifested by laryngeal obstruction and can lead to heart, pulmonary and fatal complications. Rheumatoid nodules of the larynx are often manifested by hoarseness and coughing.

\subsection{Diagnosis of rheumatoid arthritis and laryngeal rheumatoid arthritis}

Thorough anamnesis, careful examination of joints and periarticular soft tissue structures, as well as laboratory and imaging results are necessary for right diagnosis of RA. None laboratory test is specific for RA, so its diagnosis is primary clinical. A clinical examination can establish that mostly small wrists and ankles are affected relatively symmetrically. The most frequently affected joints, with decreasing frequency, are MCF, wrist joint, GIF, knee joint, MTF, shoulder joint, ankle, cervical spine, hip and temporomandibular joints. The patient whom we treated, had prominent changes on the wrists which can be clearly seen in the Figure 9.

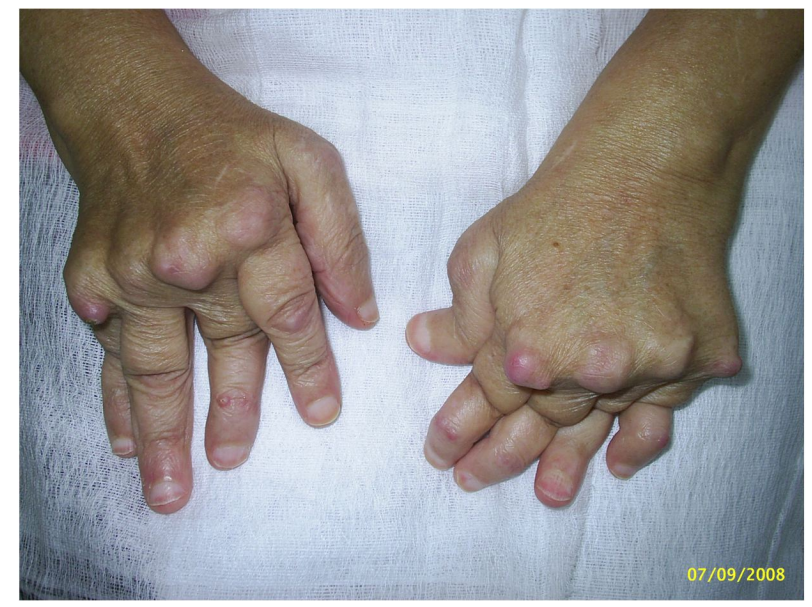

Figure 9. Hand changes of reumatoid arthritis.

Joints show inflammation with swelling, painfulness, locally high temperature and restricted movement. Atrophy of interosseus muscles of hands is a typical early sign. Joints and chordae damage can lead to deformities such as ulnar deviation, hammer like fingers and occasionally joint rigidity. Other muscle-skeletal manifestations that are usually found during the examination are tendosynovitis and joined chordae rupture during the ligament and chordae affection, the most often affected are chordae of the fourth and fifth finger extensor, periarticular osteoporosis during the localized inflammation, generalized osteoporosis during systemic chronic inflammation, changes connected to immobilization, or corticosteroid therapy and syndrom of carpal tunnel. Cutaneous changes in RA appear like subcutaneous nodules, often along the 
pressure points (for example olecranon), ulceration of feet cutis, rashes in vasculitis, palmar erythema, gangrenous pyodermia. Vascular lesions of cutis can be manifested as palpable purpura or cutis ulceration. Cardial changes in RA lead to increased cardiovascular morbidity and mortality. Myocardial infarction, myocardial disfunction and constrictive pericarditis are rare. Affection of lungs in RA can have several forms like pleural effusion, interstitial fibrosis, nodules (Caplan syndrom) and bronchiolitis obliterans, in other words ogranized pneumonia. In gastrointestinal tract, the affection of intestines is a side effect of medication action, inflammation and other diseases. Kidneys are usually intact by direct action of RA. Secondary kidney damage often happens during medicamentous therapy (nonsteroidal anti-inflammatory drugs, gold salt, cyclosporin), inflammation (amyloidosis) and joined diseases (Sjögren syndrom with kidney tubular disorders). Vascular lesions can affect any organ, but are often found on cutis where they can be manifested as palpable purpura, cutis ulcerations or digital infarcts. Hematological disorders are often manifested by secondary anemia which is normochromic-normocytic type, thrombocytosis and eosinophilia. Affection of nerves is often as in nervus medianus syndrom in the carpal tunnel. Vascular lesions, mononeuritis multiplex and cervical myelopathy can cause serious neurological prolapses. RA is manifested on eyes like keratoconjuctivitis sicca, as well as episcleritis, uveitis and nodular scleritis which can lead to scleromalacia. American college for rheumatology has determined criteria for progression, remission and functional state of RA patient. A) RA progression (clinical and radiological stages): Stage 1 (early RA) is characterized by: a) absence of destructive changes during the roentgenography examinations and b) possible radiography presence of osteoporosis; Stage 2 (advanced progression): a) radiography evidence of periarticular osteoporosis with or without light subchondral destruction of bones, b) possible light destruction of cartilage, c) possible restriction of joint movements, without joint deformities, d) joined myatrophy, e) possible soft tissue extra-articular lesions (for example nodules, tenosynovitis). Stage 3 (very advanced progression): a) radiographic evidence of cartilage and bone destruction followed by periarticular osteoporosis, b) joint deformities (for example subluxation, ulnar deviation, hyperextension) without fibrous or osseus ankylosis, c) massive myatrophy, d) possible extra-articular lesions of soft tissue (for example nodules, tenosynovitis); Stage 4: a) fibrous or osseus ankylosis and b) criteria for stage 3. B) RA remission ( $\geq 5$ below induced states that last at least two months constantly): a) morning rigidity that doesn't stop for 15 minutes, b) without weakness, c) without pain in joints, d) without cracking in joints or pain while moving, e) without soft tissue swelling in joints or chorda wraping, f) erythrocyte sedimentation lower than $30 \mathrm{~mm} / \mathrm{h}$ in women or lower than 20mm/h in men. C) Functional status of RA patients: a) Category I - completely able to fullfil everyday activities, b) Category II - able to fullfil regular personal hygiene and activities connected to their profession but limited in other activities, c) Category III - able to fullfil the activities of regular personal hygiene but limited in activities connected to their proffession and other activities that aren't connected to their profession, d) Category IV - limited to fulfill regular activities for personal hygiene, profession and activities that aren't connected to their profession. American College of Rheumatologists (ACR) and European League Against Rheumatism (EULAR) have regulated new criteria for classification of early RA, which include joint affection, autoantibodies status, answer to acute phase and symptoms duration (Aletaha, 2010). ACR/EULAR 2010 criteria: A) Joint affection (0-5): one median to large joint (0), two to 
ten median to large joints (1), one to three small joints (large joints aren't included) (2), four to ten small joints (small joints aren't included) (3), more than ten joints (at least one small joint) (5); B) Serology (0-3): negative RF and negative cell-Purkinje antibodies (APCA) (0), Light positive RF or light positive APCA (2), high positive RF or high positive APCA (3); C) Reactants of acute phase (0-1); normal CRP and normal percentage of erythrocyte sedimentation (ESR) (0), Abnormal CRP or abnormal ESR (1); D) Symptoms duration: a) shorter than 6 weeks (0), 6 weeks and more (1). Cut point for RA is 6 weeks or more. RA can be diagnosed in patients if they have: a) atypical erosions or b) long lasting disease which fullfils the previous classification criteria. Large joints are defined as: shoulder joints, elbow joints, hip joints, knee joints and ankles. Small joints are defined as: MCF, PIF, from the second to fifth MTF and interphalangeal thumb joints and carpus joints. Course of disease can be short and limited or progressive and hard. The following laboratory tests are necessary to be carried out: complete blood count with differential count, rheumatoid factor, erythrocyte sedimentation, C-reactive proteins, fibrinogen, haptoglobin, alpha-1-acid glycoprotein, alpha-1-trypsin, S-amyloid-A protein and hematocrit (Guerra, 1992). Erythrocyte sedimentation and C-reactive protein give the best information about the presence of acute phase of RA, but thrombocytosis, low level of iron in the serum and low values of hemoglobin also point to active disease (Crassi, 1998). It is also important to examine the function of liver and kidneys because of further choice of medicaments, which shows that it is necessary to carry out a complete biochemical blood analysis. Diagnosis of rheumatoid changes in the larynx includes anamnesis, clinical examination, videolaryngoscopy, computered tomography and electromyography (Amernik, 2007). Indirect laryngoscopy shows changes in the larynx in $32 \%$ of RA patients, unlike computered tomography where the changes are found in 54\%, so indirect laryngoscopy reveals mucous and great pathoanatomical changes, and computered larynx tomography reveals structural lesions (Lawry, 1984). Cricoarytenoid arthritis can be asymptomatic because many RA patients have pathological changes in cricoarytenoid joint, proved by computered tomography, but they don't have laryngeal difficulties (Brazeau-Lamontagne, 1986). Laryngoscopy in acute cricoarytenoid arthritis shows light red medially expressed swellings in the region of arytenoid, epiglottis, cricoarytenoid arthritis and vocal cords nodules that can look normal or very edematous. In chronic cricoarytenoid arthritis, we can find thickened mucosa in the region of arytenoid, interarytenoid pachydermia, uneven rima glottidis, called "bamboo nodules" because of their appearance that reminds of knots on the bamboo branch. During laryngoscopy of bamboo nodules, subepithelial sallow mass on upper surface of glottis is noticed, often mushroomlike shape and directed by its longer axis transversely to the vocal cords, and they are usually surrounded by hyperemic mucosa (Immerman, 2007; Hilgert, 2008). Direct fiber laryngoscopy can establish pathological changes in the larynx in $75 \%$ of RA patients (Brazeau-Lamontagne, 2005). The most frequent rheumatoid changes in the larynx are hyperemia of the mucosa in arytenoid subregion in $41 \%$ of the patients and edema of the same region in $28 \%$ of the patients (Amernik, 2007). Safe diagnosis of laryngeal RA is set in direct laryngoscopy by arytenoid palpation when mechanical restriction of movements in cricoarytenoid joint can be proved (Woods, 2007). Computered endovideostroboscopy allows examination of the way mucosa vibrates on the affected side, determination of lesion depth in mucous layer, confirming the unique characteristics of these lesions. In this way, we can diagnose disorders of adduction and 
lateral torsion of the vocal cords when they are present. During the palpation of these lesions in general anesthesia, we can find tough fibroid masses tightened on the deep vocal cords structures. Radiographic manifestations of the disease on wrists are characterised by swelling and mild juxta-articular osteoporosis. Radiographic indicators of cricoarytenoid joint affection are cricoarytenoid prominention (46\%), changes in thickness and volume of joint (46\%), as well as cricoarytenoid subluxation (39,9\%). Radiographic signs of erosive arthritis of cricoarytenoid joint are present in $45 \%$ of patients (Jurik 1984). Computered tomography of the larynx is a method of choice in diagnosing cricoarytenoid thickness, erosions, arytenoid subluxations, glottic or aryepiglottic nodules asymmetry and by using this method, changes are found in $72 \%$ of RA patients (Brazeau-Lamontagne, 2005). Deviation of the larynx in three surfaces is a characteristic finding for RA in the advanced stage and it includes: 1) moving of the larynx anterio-laterally, 2) rotation of the vocal cords clockwise and 3) slantedness of the larynx forward while its front aspect is lowered caudally in relation to its front part (Keenan, 1983). Similar changes on multislice scanner larynx examination in the woman patient treated at our clinic and triploid deviation of the larynx can clearly be seen in Figure 10.

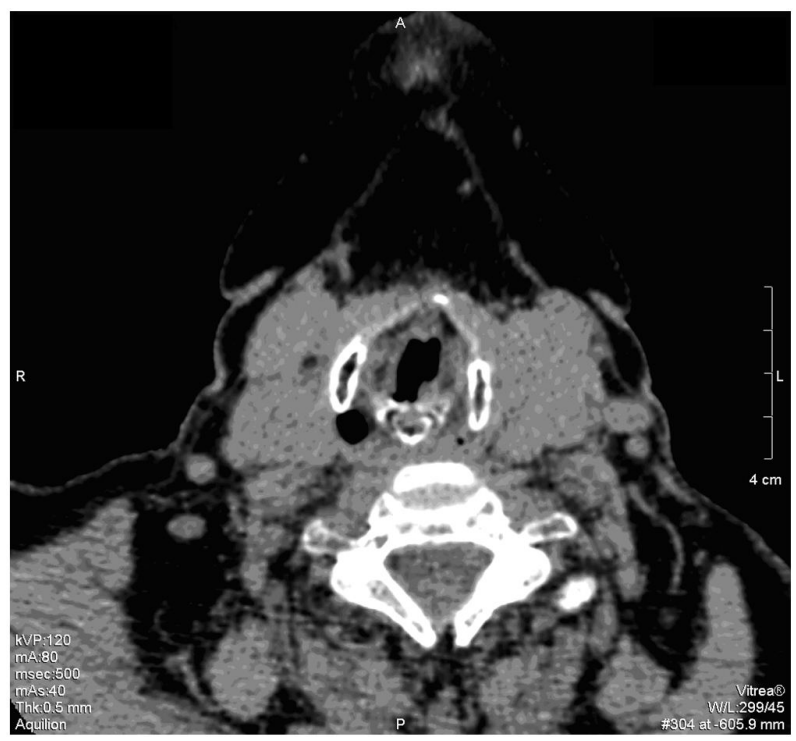

Figure 10. Sclerosis of the right arytenoid due the cricoarythenoid rheumatoid involvement. Also triplanar laryngeal deviation.

Nuclear magnetic resonance, computered tomography and scintigraphy can give useful information about pathological changes and their extension in RA. Ultrasonography is accepted for examination of joints, chordae and bursa affection in RA and it can advance early clinical diagnosis and following of patients, showing details such as synovial thicknesses in finger joints (Grassi W, 1998). In RA patients, electromyographic examinations of internal 
thyroarytenoid muscles show mutually normal bioelectric stimulation of thyroarytenoid muscles during phonation, while at rest there is no denervation activity (Tarnowska, 2004).

\subsection{Complications of laryngeal rheumatoid arthritis}

Complications of RA can begin to develop within several months since the appearance of clinical symptoms, so timely refering to a rheumatologist or his consultation are necessary for the beginning of treatment with DMARD (disease-modifying antireumatic drugs). A great number of acute respiratory insufficiency cases caused by rheumatoid arthritis in the larynx have been described (Chalmers, 1979; McGeehan, 1989). Acute respiratory insufficiency in RA patients can be provoked by bacterial infections of the larynx, mechanical larynx lesions or acute exacerbation of cricoarytenoid arthritis (Bolten, 1991; Geterud, 1986). Laryngeal obstruction required surgical tracheotomy of RA patients (Takakura, 2005; Jol, 1997; Daver, 1994; Ten Holter, 1988; Peters, 2011; Bossingham, 1996; Funk, 1975). Tracheotomy is necessary in $10-25 \%$ of patients with chronic cricoarytenoiditis (Tarnowska, 2004). Acute obstruction of airways is often connected to cervical spine ankylosis and impossibility of its extension (Miller, 1994). Cervical spine ankylosis was also present with the patient that we treated, it can easily be seen in Figure 6. and it can threaten surgical tracheotomy (Yonemoto, 2005).

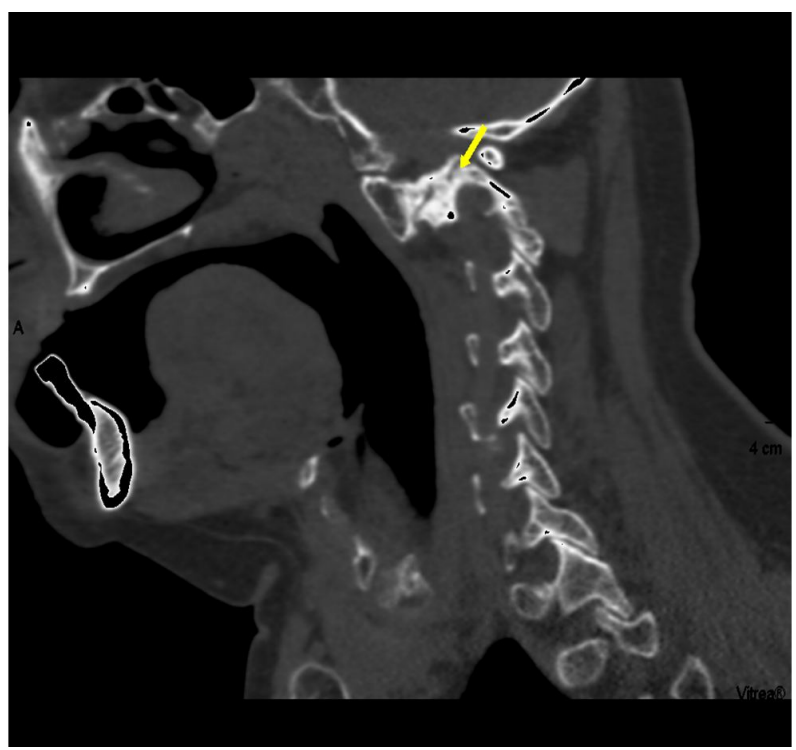

Figure 11. Atalantoccipital joint ankylosis. Arrow indicates patological process of cervical spine.

Vertical penetration of cerebral vertebra cusp was the most important manifestation of cervical spine disease, and one of the laryngeal deviation causes is the scoliotic trachea and the larynx deformation because of neck shortening as a consequence of the second cervical vertebra cusp penetration. Another machanism is rotational deformity of cervical vertebra 
caused by asymmetric osseous erosions (Keenan, 1983). Besides cricoarytenoid and cervical vertebra ankylosis, treatment of RA patients is also difficult because of temporomandibular joint ankylosis (Okuda, 1992; McGeehan, 1989). These pathological changes of RA patients can make endotracheal intubation very difficult and dangerous, especially if there is a triploid deviation of the larynx on computered tomography (Bamshad, 1989). Rheumatoid cricoarytenoid arthritis was complicated by ulcerous necrosis of cricoid esophagostenosis and therefore the patient underwent total laryngectomy (Montgomery, 1980).

\subsection{Differential diagnosis of rheumatoid arthritis and laryngeal rheumatoid arthritis}

Differential diagnosis is directed to artropathies caused by infection, seronegative spondyloartropathies and other connective tissue diseases such as systemic lupus eritematodes (Harris, 2005; Akil, 1995; Nanke, 2001).

RA should be distinguished from a wide range of diseases that are characterized by clinically prominent synovitis, such as viral, reactive and psoriatic arthritis as well as enteroarthritis and we can come to differential diagnosis by eliminating, because there isn't a specific test for RA (Grassi, 1998). Arthritis of cricoarytenoid joint is also caused by gout, mumps, tuberculosis, syphilis, gonorrhea, Tietz syndrom, lupus eritematodes and injuries (Fried, 1991). Rheumatoid nodules of the larynx as initial signs of systemic lupus eritematodes are described in the literature (Schwartz, 1980). Rheumatoid nodules of the larynx can be differentially diagnostic problem if they are mixed up with vascular lesions (Friedman, 1975). It is often important to distinguish by differential diagnosis asthma and psychoneurosis from cricoarytenoid joint arthritis which is rarely manifested by acute laryngeal obstruction and colapse (Leicht 1987; Absalom 1998). Secondary amyloidosis during rheumatoid arthritis or secondary Sjögren syndrom are rarely causes for laryngeal symptoms (Bayar, 2003). The case of RA and systemic sclerosis union is also described, which led to mutual immobility of the vocal cords and was manifested by dysphonia and dyspnea as main symptoms and treatment by sphygmic doses of methylprednisolone led to slow improvement (Ingegnoli, 2007). With other autoimmune diseases, transversal, white-yellow, striped lesions can be found, in the median part of membranous link of the vocal cords, mostly bilateral, but they aren't symmetrical (Ylitalo, 2003). Rheumatoid cricoarytenoid arthritis should be distinguished from neurogenic disorders, traumatic changes, infections, neoplastic processes and psychosomatic illnesses (Bolten, 1991; Chen, 2005). The most difficult differential diagnosis is in cricoarytenoid ankylosis and bilateral paresis/paralysis of recurrent laryngeal nerves. Mutual immobility of cricoarytenoid joint and Hashimoto thyroiditis are next differentially diagnostic problem which requires multidiscipline approach (Stojanovic, 2010). Then normal electromyogram of vocal muscles and fixation of cricoarytenoid joints during laryngoscopy set by application of laryngoscopic claws, confirm the diagnosis of ankylosis. Differential diagnosis of these two conditions is possible by using electromyography and laryngoscopy, and mutual fixation of the arytenoid cartilages is confirmed with long-term endotracheal intubation (in $68,8 \%$ of patients), short-term endotracheal intubation (in 9,4\%), Wegener granulomatosis (in 9,4\%) of rheumatoid arthritis (in 6,3\%) of previous surgery in the larynx (in $3,1 \%$ ) and caustic ingestion (in 3,1\%) (Eckel, 2003). 


\subsection{Treatment of rheumatoid arthritis and laryngeal rheumatoid arthritis}

The aims of early prevention and early treatment of RA are to reduce pain, inflammation and inability, to prevent radiologically found damages and progression and to reduce the development of comorbidity. Joint damage in rheumatoid arthritis begins a few weeks since the begining of the disease symptoms and that's why the early treatment reduces the disease progression rate (Emery, 2002). Pharmacotherapy generally includes several groups of medications: nonsteroidal anti-inflammatory drugs (NSAID) for pain control, oral or intra-articular glucocorticoids in low doses and start with DMARD. "Reverse pyramid" approach is required in RA treatment today, when DMARD are started immediately in order to slow down the disease progression as soon as possible (Rindfleisch, 2005). This approach is accepted on the basis of several facts: joint damages start in the early phase of the disease (Emery, 2002), DMARD have a significant use when they are used in the early phase of the disease, the uses of DMARD can be helped when the medications are used in the combination (Pincus, 1999; Lipsky, 2000; Weinblatt, 2004), a great number of medications from this group with positive evidence of useful effects are accessible. RA patients of medium stage and normal radiographic results should start the treatment with hydroxychloroquine, sulphasalazine or minocycline, although methotrexate is also a possibility. Patients with heavier stage of disease or radiographic changes should start treatment with methotrexate. If the disease symptoms aren't controlled well by mentioned medications, leflunomid or combined therapy should be taken into consideration (methotrexate together with one medication of newer generation). For initial RA treatment for reducing pain and joint swelling together with the combination of the mentioned medications, NSAID, salicylate or ciclooxygenease- 2 inhibitors should be used. These medications can't be used independently because they don't change clinical course of RA. Glucocorticoids, usually in the dose that is equivalent to $10 \mathrm{mg}$ of prednisone a day are highly important for freeing from RA symptoms and they can slow down joint damage (Kirwan, 1995). Their dosing should be kept at minimum because of a great risk of unwanted effects, which include osteoporosis, cataract, hyperadrenocorticism and altered glycemia levels. American college for rheumatology has recommended the intake of $1500 \mathrm{mg}$ of calcium and 400-800 IU of vitamin D a day. The most often used medications for RA treatment are methotrexate, hydroxychloroquine, sulphasalazine, leflunomide, infliximab and etanercept. Newer DMARD are leflunomide, antagonists tumor necrosis factor (TNF) and anakinra. Pharmacotherapeutic approaches for RA are very different depending on certain studies. One of such approaches is a combination of these two medications from the DMARD group, mainly methotrexate and sulphasalazine or methotrexate and cyclosporine (Dougados, 1999; Tugwell, 1995). Combination of methotrexate, sulphasalazine and high doses of corticosteroids has brought up to prolonged effects on radiographic progression in comparison to monotherapy by sulphasalazine (Landewe, 2002). In the two-year study, 197 RA patients were chosen by coincidence to take therapeutic protocol with four medications, methotrexate, sulphasalazine, hydroxychloroquine and prednisolone (5mg/a day) or individual medication from DMARD where it has been noticed that greater number of patients in remission got combined therapy, while fewer number of patients in remission were in the group of monotherapy by some other medication from DMARD group (Korpela, 2004). In some studies, cricoarytenoid arthritis treatment in a 65- 
year-old male patient and 56-year-old female patient was carried out by local, intra-articular injections of triamcinolone combined with prednisolone (Jol, 1997; Simpson, 1980; Habib, 1977). Systemic application of corticosteroids brought up to significant mobility of the arytenoid cartilages in a 63-year-old patient (Jurik, 1985). Beclomethasone diproprionat in the treatment of rheumatoid changes in the larynx was useful (Sladek, 1983). Surgical approach to immobility of the vocal cords from paramedial position, in other words rheumatoid ankylosis of cricoarytenoid joints implies mobilizational and laterofixational techniques (Ejnell, 1985). Arytenoid adduction surgery was carried out successfully in a 57-year-old female patient who didn't have dyspnea year and a half after the surgery (Kumai, 2007). Endoscopic arytenoidectomy is usually a surgery of choice (Koufman, 2003).

\section{Conclusion}

Rheumatoid arthritis is a disease of unknown cause with several assumed etiological theories, but pathoanatomical and pathophysiological changes are mostly familiar. It is manifested on different organs and tissues and about $25 \%$ of all patients have clinical manifestations in the larynx. Patients with RA manifested on more than one joint, must be sent to and examined by a rheumatologist 6 weeks since the beginning of the disease symptoms. Joint and bones swelling points to early arthritis especially if at least two joints are involved and/or morning rigidity lasts longer than 30 minutes and/or if there is an affection of metacarpophalangeal and/or metatarsophalangeal joints (Emery, 2002). Following the disease course includes counting of painful and swollen joints, complete cooperation between the patient and the physician, determining erythrocyte sedimentation and $\mathrm{C}$ - reactive protein. Disease activities should be followed in the intervals from 1 to 3 months until the remission period is reached. Structural damages must be followed rardiographically every 6 to 12 months during the first several years. Family doctor must think about the structural damage of the larynx in the patients with advanced arthritis and he must send these patients to periodical otorhinolaryngological examinations every 1 to 3 months. At that time, it is necessary to carry out indirect laryngoscopy and graphic flow/volume which is enough for the initial screening. Forced inspiratory/expiratory relationship between the flow and volume provide a simple non-invasive test for revealing stenosis in upper airways. Pathological results of screening cause additional examinations by fiberoptical laryngoscopy, laryngomicroscopy with the examination of the arytenoid cartilages fixation, helped by multislice scanner larynx examination every six months to a year, computered stroboscopy and electromyography of the larynx. This is important because laryngoscopy provides better view of the mucous and functional integrity preservation, and multislice scanner larynx examination offers more precise visualisation of the structural changes. Periodical otorhinolaryngological examinations should be routine when treating patients with rheumatoid arthritis and they are always undertaken when family doctor and/or the rheumatologist of the clinic find the smallest disease progression on laryngeal and/or extralaryngeal localizations. Then, together with basic rheumatological therapy, intra-articular application of corticosteroid medications needs to be applied into every sick cricoarytenoid joint. When conservative treatment fails, 
after providing airways by tracheostomy, it is indicated to carry out endoscopic arytenoidectomy which presents a surgery of choice. For patients of extremely bad state to bear laryngeal surgery, or with those patients where surgical procedures failed to provide adequate airway, permanent tracheostomy is the final therapeutic possibility. In RA patients where a surgery in general endotracheal anesthesia is indicated, the otorhinolaryngologists inform the anesthesiologist after every examination about every laryngeal disorder. Anesthesiological risk is always present in the patients with rheumatoid arthritis in the larynx during endotracheal intubation and immediately after the extubation (Segebarth, 2007). In these patients, a careful search for cricoarytenoid arthritis is the basic thing, especially in those with laryngeal stridor which can be inforced after general anesthesia.

\section{Acknowledgements}

I would like to give credit to my wife Tatjana, my daughter Nina and my son Luka for their support and immense patience during elaboration of this chapter, as well as for their recognition of the importance of this work in diagnosis and treatment of all rheumatoid arthritis patients.

\section{Author details}

Stevan Stojanović ${ }^{*}$ and Branislav Belić

*Address all correspondence to: stevan67@gmail.com

Faculty of Medical Sciences, University of Kragujevac, Republic of Serbia

\section{References}

[1] Firestein, G. S. (2005). Etiology and pathogenesis of rheumatoid arthritis. Kelley's Textbook of rheumatology, Ruddy, S, Harris, E.D, Sledge, C.B. et al, (Ed.), 996-1042, 7th ed, W.B. Saunders, 0721601413, Philadelphia, USA.

[2] Aletaha, D., Neogi, T., Silman, A. J., Funovits, J., Felson, D. T., \& Bingham, C. O. (2010). Rheumatoid arthritis classification criteria: an American College of Rheumatology/European League Against Rheumatism collaborative initiative. Arthritis Rheum, 62(9), 2569-81.

[3] Goldring, S. R. (2000). A 55-year-old woman with rheumatoid arthritis. JAMA, 283, 524-31.

[4] Kuder, S. A., Peshimam, A. Z., \& Agraharam, S. (2002). Environmental risk factors for rheumatoid arthritis. Rev Environ Health, 17, 307-15. 
[5] Merlino, L. A., Curtis, J., Mikuls, T. R., et al. (2004). Vitamin D intake is inversely associated with rheumatoid arthritis: results from the Iowa Women's Health Study. Arthritis Rheum, 50, 72-7.

[6] Emery, P., Breedveld, F. C., Dougados, M., et al. (2002). Early referral recommendation for newly diagnosed rheumatoid arthritis: evidence based development of a clinical guide. Ann Rheum Dis, 61, 290-7.

[7] Harris, E. D. (2005). Clinical features of rheumatoid arthritis. In: Kelley's Textbook of rheumatology Ruddy, S, Harris, ED, Sledge, C.B, et al, (Ed.), 1043-78, 7th ed, W.B. Saunders, 0721601413, Philadelphia, USA.

[8] Akil, M., \& Amos, R. S. (1995). ABC of rheumatology. Rheumatoid arthritis-I: clinical features and diagnosis. BMJ, Review, 310, 587-90, 0959-8138.

[9] Bridger, M. W., Jahn, A. F., \& van Nostrand, A. W. (1980). Laryngeal rheumatoid arthritis. Laryngoscope, 90(2), 296-303, 0023-852X.

[10] Lofgren, R. H., \& Montgomery, W. W. (1962). Incidence of Laryngeal Involvement in Rheumatoid Arthritis. N Engl J Med, 267, 193-5.

[11] Bonner, F. M. 3rd. (1977). Rheumatoid nodule. Pathological quiz case 1. Arch Otolaryngol, 103(2), 112-4.

[12] Ferdynus-Chromy, J., \& Wagner, T. (1977). Comparative studies of synovial membranes of cricoarytenoid and knee joints in rheumatoid arthritis. Reumatologia, 15(1), 13-21.

[13] Grassi, W., De Angelis, R., Lamanna, G., \& Cervini, C. (1998). The clinical features of rheumatoid arthritis. Eur J Radiol, 27(1), 18-24, 0720-048X.

[14] Mackenzie, M. (1880). Diseases of the pharynx, larynx and trachea, William Wood \& Co., New York.

[15] Mackenzie, G. H. (1894). Rheumatism of the larynx. Edin Med J, 40, 507-9.

[16] Voulgari, P. V., Papazisi, D., Bai, M., et al. (2005). Laryngeal involvement in rheumatoid arthritis. Rheumatol Int, 25(5), 321-5.

[17] Kerstens, P. J., Boerbooms, A. M., Jeurissen, M. E., et al. (1992). Accelerated nodulosis during low dose methotrexate therapy for rheumatoid arthritis. An analysis of ten cases. J Rheumatol, 19, 867-71, 0315-162X.

[18] Fried, M.P., \& Shapiro, J. (1991). Acute and chronic laryngeal infections. Otolaryngology, edn 3, Paperella, M.M., Shumrick, D.A., Gluckman, J. I., Meyerhoff, W.L., (Ed), W. B. Saunders, Philadelphia, USA. 0721615074 9780721615073, 2245-56.

[19] Webb, J., \& Payne, W. H. (1972). Rheumatoid nodules of the vocal folds. Ann Rheum Dis, 31, 122-5.

[20] Bienenstock, H., Ehrlich, G. E., \& Breyberg, R. H. (1963). Rheumatoid arthritis of the cricoarytenoid joints: a clinicopathologic study. Arthritis Rheum, 6, 48-63. 
[21] Pearson, J. E. (1957). Rheumatoid arthritis of the larynx. Br Med J, 2, 1047, 0007-1447.

[22] Copeman, W. S. (1957). Rheumatoid arthritis of the cricoarytenoid joints. Br Med J, 1(5032), 1398-9.

[23] Bayar, N., Kara, S. A., Keles, I., et al. (2003). Cricoarytenoid in rheumatoid arthritis: Radiologic and clinical study. J Otolaryngol, 32(6), 373-8.

[24] Charlin, B., Brazeau-Lamontagne, L., Levesque, Ry., et al. (1985). Cricoarytenoiditis in rheumatoid arthritis: Comparision of fibrolaryngoscopic and high resolution computerized tomographic findings. J Otolaryngol, 14, 381-6.

[25] Hamdan, A. L., El -Khatib, M., Dagher, W., et al. (2007). Laryngeal involvement in rheumatoid arthritis. M E J Anesth, 19(2), 335-46.

[26] Chen, J. J., Branstetter, B. F., \& Myers, E. N. (2005). Cricoarytenoid rheumatoid arthritis: an important consideration in aggressive lesions of the larynx. Am J Neuroradiol, 26(4), 970-2.

[27] Lawry, G. V., Finerman, M. L., Hanafee, W. N., Mancuso, A. A., Fan, P. T., \& Bluestone, R. (1984). Laryngeal involvement in rheumatoid arthritis A clinical, laryngoscopic, and computerized tomographic study. Arthritis Rheum, 27(8), 873-82.

[28] Jurik, A. G., \& Pedersen, U. (1984). Rheumatoid arthritis of the crico-arytenoid and crico-thyroid joints: a radiological and clinical study. Clin Radiol, 35(3), 233-6.

[29] Ingegnoli, F., Galbiati, V., Bacciu, A., Zeni, S., \& Fantini, F. (2007). Bilateral vocal fold immobility in a patient with overlap syndrome rheumatoid arthritis/systemic sclerosis. Clin Rheumatol, 26(10), 1765-7.

[30] Leicht, M. J., Harrington, M. H., \& Davis, D. E. (1987). Cricoarytenoid arthritis: A cause of laryngeal obstruction. Annals of Emergency Medicine, 16(8), 885-8.

[31] Amernik, K. (2007). Glottis morphology and perceptive-acoustic characteristics of voice and speech in patients with rheumatoid arthritis. Ann Acad Med Stetin, 53(3), 55-65, 1427-440X.

[32] Amernik, K., Tarnowska, C., Brzosko, I., Grzelec, H., \& Burakl, M. (2007). Glottis morphology in rheumatoid arthritis. Otolaryngol Pol, 61(1), 85-90.

[33] Immerman, S., Sulica, L., \& Bamboo, Nodes. (2007). Otolaryngol Head Neck Surg, 137(1), 162-3.

[34] Braverman, I., Malatskey, S., \& Avior, G. (2007). Bilateral vocal cord paralysis due to rheumatoid arthritis. Harefuah, 146(2), 92-4.

[35] Takakura, K., Hirakawa, S., Kudo, K., Mori, M., Kitano, T., \& Noguchi, T. (2005). Cricoarytenoid arthritis diagnosed after tracheostomy in a rheumatoid arthritis patient. Masui, 54(6), 690-3. 
[36] Yonemoto, N., Nagahata, T., Nishimura, T., Kato, H., Kitaguchi, K., \& Furuya, H. (2005). Difficult airway management during emergency tracheostomy in a patient with severe rheumatoid arthritis. Masui, 54(1), 39-41.

[37] Tarnowska, C., Amernik, K., Matyja, G., Brzosko, I., Grzelec, H., \& Burak, M. (2004). Fixation of the crico-arythenoid joints in rheumatoid arthritis--preliminary report. Otolaryngol Pol, 58(4), 843-9.

[38] Ylitalo, R., Heimbürger, M., \& Lindestad, P. A. (2003). Vocal fold deposits in autoimmune disease--an unusual cause of hoarseness. Clin Otolaryngol Allied Sci, 28(5), 446-50.

[39] Eckel, H. E., Wittekindt, C., Klussmann, J. P., Schroeder, U., \& Sittel, C. (2003). Management of bilateral arytenoid cartilage fixation versus recurrent laryngeal nerve paralysis. Ann Otol Rhinol Laryngol, 112(2), 103-8.

[40] Jol, J.A., van Deelen, G.W., \& Dinant, H.J. (1997). Sore throat in rheumatoid arthritis: 2 patients with cricoarytenoid arthritis. Ned Tijdschr Geneeskd, 141(32), 1567-70, 0028-2162.

[41] Miller, F. R., Wanamaker, J. R., Hicks, D. M., \& Tucker, H. M. (1994). Cricoarytenoid arthritis and ankylosing spondylitis. Arch Otolaryngol Head Neck Surg, 120(2), 214-6.

[42] Daver, L., Toussirot, E., \& Acquaviva, P. C. (1994). Severe laryngeal involvement in rheumatoid arthritis requiring permanent tracheostomy. Rev Rhum Ed Fr, 61(7-8), 550-3, 1169-8330.

[43] Okuda, Y., Takasugi, K., Imai, A., Hashimoto, F., Kondo, Y., Hatinota, M., et al. (1992). Cricoarytenoid joint involvement in rheumatoid arthritis. Ryumachi, 32(3), 245-51.

[44] Guerra, L. G., Lau, K. Y., \& Marwah, R. (1992). Upper airway obstruction as the sole manifestation of rheumatoid arthritis. J Rheumatol, 19(6), 974-6, 0315-162X.

[45] Bolten, W. (1991). The cricoarytenoid joint in chronic polyarthritis. Z Rheumatol, 0340-1855, 50(1), 1-5.

[46] Dockery, K. M., Sismanis, A., \& Abedi, E. (1991). Rheumatoid arthritis of the larynx: the importance of early diagnosis and corticosteroid therapy. South Med J, 84(1), 95-6.

[47] Ten, Holter. J. B., Van Buchem, F. L., \& Van Beusekom, H. J. (1988). Cricoarytenoid arthritis may be a case of emergency. Clin Rheumatol, 7(2), 288-90.

[48] Gatland, D.J., Keene, M.H., \& Brookes, J.D. (1988). Cricoid necrosis in laryngeal rheumatoid arthritis. J Laryngol Otol, 102(3), 271-5, 0022-2151.

[49] Geterud, A., Ejnell, H., Månsson, I., Sandberg, N., Bake, B., \& Bjelle, A. (1986). Severe airway obstruction caused by laryngeal rheumatoid arthritis. J Rheumatol, 13(5), 948-51. 
[50] Ejnell, H., Bake, B., Månsson, I., Hallén, O., Sandberg, N., Geterud, A., \& Bjelle, A. (1985). New mobilization and laterofixation procedure for cricoarytenoid joint ankylosis in rheumatoid arthritis. Ann Otol Rhinol Laryngol, 94(5 Pt 1), 442-4, 0003-4894.

[51] Jurik, A. G., Pedersen, U., \& Nøorgård, A. (1985). Rheumatoid arthritis of the cricoarytenoid joints: a case of laryngeal obstruction due to acute and chronic joint changes. Laryngoscope, 95(7 Pt 1), 846-8, 0023-852X.

[52] Sladek, G. D., Vasey, F. B., Saraceno, C., Davis, B. J., Germain, B. F., \& Espinoza, L. R. (1983). Beclomethasone dipropionate in the treatment of the rheumatoid larynx. J Rheumatol, 10(3), 518-9, 0315-162X.

[53] Simpson, G. T., Javaheri, A., \& Janfaza, P. (1980). Acute cricoarytenoid arthritis: local periarticular steroid injection. Ann Otol Rhinol Laryngol, 89 (6 Pt 1), 558-62, 0003-4894.

[54] Schwartz, I. S., \& Grishman, E. (1980). Rheumatoid nodules of the vocal cords as the initial manifestation of systemic lupus erythematosus. JAMA, 244(24), 2751-2.

[55] Montgomery, W. W., \& Goodman, M. L. (1980). Rheumatoid cricoarytenoid arthritis complicated by upper esophageal ulcerations. Ann Otol Rhinol Laryngol, 89(1 Pt 1), 6-8, 0003-4894.

[56] Chalmers, A., \& Traynor, J. A. (1979). Cricoarytenoid arthritis as a cause of acute upper airway obstruction. J Rheumatol, 6(5), 541-2, 0315-162X.

[57] Friedman, B. A. (1975). Rheumatoid nodules of the larynx. Arch Otolaryngol, 101(6), 361-3.

[58] Abadir, W. F., \& Forster, P. M. (1974). Rheumatoid vocal cord nodules. J Laryngol Otol, 0022-2151, 88(5), 473-8.

[59] Gotze, M., Andersen, R. B., Westergaard, O., \& Andersen, L. A. (1973). Rheumatoid arthritis in the crico-arythenoid joints. Ugeskr Laeger, 136(1), 39-41.

[60] Kubiak-Socha, E. (1973). Case of rheumatoid arthritis with involvement of cricoarytenoid articulations. Wiad Lek, 26(11), 1067-8.

[61] De Gandt, J. B. (1969). Cricoarytenoid ankylosis. Acta Otorhinolaryngol Belg, 23(6), 603-11.

[62] Copeman, W. S. (1968). Rheumatoid arthritis and the crico-arytenoid joints. Br J Clin Pract, 22(10), 421-2.

[63] Peters, J. E., Burke, C. J., \& Morris, V. H. (2011). Three cases of rheumatoid arthritis with laryngeal stridor. Clin Rheumatol, 30(5), 723-7.

[64] Mc Geehan, D. F., Crinnion, J. N., \& Strachan, D. R. (1989). Life-threatening stridor presenting in a patient with rheumatoid involvement of the larynx. Archives of Emergency Medicine, 6, 274-6. 
[65] Fisher, B. A., Dolan, K., Hastings, L., Mc Clinton, C., \& Taylor, P. C. (2008). Prevalence of subjective voice impairment in rheumatoid arthritis. Clin Rheumatol, 27, 1441-3.

[66] Hilgert, E, Toleti, B, Kruger, K, \& Nejedlo, I. (2008). Hoarseness Due to Bamboo Nodes in Patients with Autoimmune Diseases: A Review of Literature. Journal of Voice, 22(3), 343-50, 0892-1997.

[67] Lehmann, T., Nef, W., Stalder, B., Thomson, D., \& Gerber, N. J. (1997). Fatal postoperative airway obstruction in a patient with rheumatoid arthritis. Annals of the Rheumatic Diseases, 56, 512-3.

[68] Bossingham, D. H., \& Simpson, F. G. (1996). Acute laryngeal obstruction in rheumatoid arthritis. BMJ, 312(7026), 295-6.

[69] Segebarth, B., \& Limbird, T. J. (2007). Perioperative Acute Upper Airway Obstruction Secondary to Severe Rheumatoid Arthritis. The Journal of Arthroplasty, 22(6), 907, 0883-5403.

[70] Hart, F. D. (1966). Complicated rheumatoid disease. Br Med J, 2(5506), 131-5.

[71] Kumai, Y., Murakami, D., Masuda, M., \& Yumoto, E. (2007). Arytenoid adduction to treat impaired adduction of the vocal fold due to rheumatoid arthritis. Auris Nasus Larynx, 34(4), 545-8.

[72] Absalom, A. R., Watts, R., \& Kong, A. (1998). Airway obstruction caused by rheumatoid cricoarytenoid arthritis. Lancet, 351(9109), 1099-100.

[73] Keenan, M. A., Stiles, C. M., \& Kaufman, R. L. (1983). Acquired laryngeal deviation associated with cervical spine disease in erosive polyarticular arthritis. Use of the fiberoptic bronchoscope in rheumatoid disease. Anesthesiology, 58(5), 441-9.

[74] Bamshad, M., Rosa, U., Padda, G., \& Luce, M. (1989). Acute upper airway obstruction in rheumatoid arthritis of the cricoarytenoid joints. South Med J, 82(4), 507-11.

[75] Stojanović, S. P., Zivić, Lj., Stojanović, J., \& Belić, B. (2010). Total fixation of cricoarytenoid joint of a patient with rheumatoid arthritis and Hashimoto thyroiditis. Srp Arh Celok Lek, 138(3-4), 230-2, 0370-8179.

[76] Funk, D., \& Raymon, F. (1975). Rheumatoid arthritis of the cricoarytenoid joints: an airway hazard. Anesth Analg, 54(6), 742-5.

[77] Pincus, T., O’Dell, J. R., \& Kremer, J. M. (1999). Combination therapy with multiple disease-modifying antirheumatic drugs in rheumatoid arthritis: a preventive strategy. Ann Intern Med, 131, 768-74.

[78] Lipsky, P. E., van der Heijde, D. M., St, Clair. E. W., Furst, D. E., Breedveld, F. C., Kalden, J. R., et al. (2000). Infliximab and methotrexate in the treatment of rheumatoid arthritis. N Engl J Med, 343, 1594-602.

[79] Weinblatt, M. E., Keystone, E. C., Furst, D. E., Moreland, L. W., Weisman, M. H., Birbara, C. A., et al. (2003). Adalimumab, a fully human anti-tumor necrosis factor alpha 
monoclonal antibody, for the treatment of rheumatoid arthritis in patients taking concomitant methotrexate: the ARMADA trial. Arthritis Rheum, 48, 35-45.

[80] Kirwan, J. R. (1995). Arthritis and Rheumatism Council Low-Dose Glucocorticoid Study Group. The effect of glucocorticoids on joint destruction in rheumatoid arthritis. N Engl J Med, 333, 142-6, 0028-4793.

[81] Dougados, M., Combe, B., Cantagrel, A., et al. (1999). Combination therapy in early rheumatoid arthritis: a randomised, controlled, double blind 52 week clinical trial of sulphasalazine and methotrexate compared with the single components. Annals of the Rheumatic Diseases, 58, 220-5.

[82] Tugwell, P., Pincus, T., Yocum, D., et al. (1995). Combination therapy with cyclosporine and methotrexate in severe rheumatoid arthritis. The Methotrexate-Cyclosporine Combination Study Group. N Engl J Med, 333, 137-41.

[83] Landewe, R. B., Boers, M., Verhoeven, A. C., et al. (2002). COBRA combination therapy in patients with early rheumatoid arthritis: long-term structural benefits of a brief intervention. Arthritis and Rheumatism, 46, 347-56.

[84] Korpela, M., Laasonen, L., Hannonen, P., et al. (2004). Retardation of joint damage in patients with early rheumatoid arthritis by initial aggressive treatment with diseasemodifying anti-rheumatic drugs: five-year experience from the FIN-RACo study. Arthritis and Rheumatism, 50, 2072-81, 0300-9742.

[85] Koufman, J. A., \& Belafsky, P. C. (2003). Infectious and Inflammatory Diseases of the Larynx. Ballenger's Otorhinolaryngology Head and Neck Surgery, Snow J.B., Jr, Ballenger J.J., 1207, BC Decker Inc, 1-55009-197-2, Hamilton, Ontario.

[86] Woodson, G. E. (2007). Hoarseness and Laryngeal Paralysis. Head and Neck Manifestations of Systemic Disease, Harris, J. P., Weisman, M. H., 517-525, Informa Healthcare Inc, 0-8493-4050-0, New York, USA.

[87] Brazeau-Lamontagne, L., Charlin, B., Levesque, R. Y., et al. (1986). Cricoarytenoiditis: CT assessment in rheumatoid arthritis. Radiology, 158(2), 463-6. 
